\title{
DELEUZE. COREOGRAFÍAS ABSTRACTAS. POR UN VOCABULARIO MENOR
}

Deleuze. Abstract choreographies. For a minor vocabulary.

\author{
Willy Thayer \\ Universidad Metropolitana de Ciencias de la Educación, Santiago, Chile \\ wthayerm@gmail.com
}

\section{Resumen}

Este ensayo elabora un concepto de performance. Básicamente lo hace utilizando el imaginario terminológico y referencial de los escritos y cursos de Deleuze sobre pintura. En un par de ocasiones utiliza también terminologías de sus libros y cursos sobre cine. La dificultad, el nudo de este concepto, y de su exposición, reside en que la performance pictórica solo acontece cuando su enunciación desestabiliza los enunciados usuarios y los marcos estructurales de reconocimiento en medios de los que se ejerce, y de los que se sirve para cifrarse. La performance en pintura se erige en cada caso, entonces, como una enunciación que no se deja estar, no se deja morir en los enunciados que rigurosamente utiliza para escribirse. La exposición de este concepto fracasará, también, en la misma medida en que los enunciados que utilice para proponerlo, acaben clausurándolo, determinándolo narrativamente.

Palabras clave: performance, impresión, fuerza, mutación, manierismo, inminencia.

\begin{abstract}
This essay elaborates a concept of performance. It basically does so by using the terminological and referential imaginary of Deleuze's courses and writings on painting. In a couple of instances, it also uses terminologies from his books and courses on cinema. The difficulty, the knot of this concept, and its exposition, resides in the fact that pictorial performance only occurs when its enunciation destabilizes the customary and structural frames of recognition in the midst of which it is exercised, and which it makes use of for its own enactment. Performance in painting is erected in each case, then, as an enunciation that does not allow itself to be stabilized, that does not allow itself to die in the statements which it rigorously uses to write itself out. The exposition of this concept will fail, also, insofar as the statements it uses to display it, end up enclosing it, determining it narratively.
\end{abstract}

Keywords: performance, impression, force, mutation, mannerism, imminence, felt.

Fecha de Recepción: 01/07/2019 - Fecha de Aceptación: 26/11/2019 
Nuestro error está en creer que lo que se mueve son elementos cualesquiera exteriores a las cualidades. Pero las cualidades mismas son puras vibraciones que cambian al mismo tiempo que se mueven los pretendidos elementos. ${ }^{1}$ Gilles Deleuze

El movimiento es una traslación en el espacio. Ahora bien, cada vez que hay traslación de partes en el espacio, hay también cambio cualitativo en un todo. En Materia y memoria Bergson daba múltiples ejemplos. Un animal se mueve, pero no para nada: se mueve para comer, para migrar, etc. Diríase que el movimiento supone una diferencia de potencial, y que se propone colmarla. Sí considero abstractamente partes o lugares,

$A$ y $B$, no comprendo el movimiento que va del uno al otro. Pero estoy en A y tengo hambre, y en $B$ hay alimento. Una vez que he llegado a B y he comido, lo que ha cambiado no es sólo mi estado, es el estado del todo que comprendía a $B, A$ y todo lo que había entre los dos [...]. Si se piensa en puros átomos, sus movimientos, que dan fe de una acción recíproca de todas las partes de la materia, expresan necesariamente modificaciones, perturbaciones, cambios de energía en el todo. Lo que Bergson descubre más allá de la traslación es la vibración. ${ }^{2}$ Gilles Deleuze

\section{Impresión}

"Toda mi investigación [en pintura] se extiende sobre la noción de catástrofe" (Deleuze 2007 22). Tal vez toda la pintura, en la singularidad de su caso a caso, y no sólo el canon que Deleuze acota en algunos de sus cursos y libros ${ }^{3}$, pueda leerse desde esta noción. No intenta con ello establecer una episteme pictórica general. Tampoco retomar preguntas de siempre que enmarquen y conduzcan su indagatoria. Procura "dejarse llevar"4, dejarse ir en una "impresión" (Ibid.), una "conmoción" (Id. 23). Con las palabras impresión o conmoción parece referir la experiencia de una fuerza desencadenándose (Id. 91-93, 209) del orden perceptual, intencional, fenoménico. ¿Estético?

Fuerza, para Deleuze, "constituye antes que nada una instancia muda, estúpida y brutal que golpea y se impone. La Historia de la Filosofía, la opone al logos" (Zouravichbili 2004). La fuerza, la violencia de la “impresión", la "conmoción" del golpe de luz, de color único, irrepetible - un Pollock después de 1947, dice, por ejemplo, o un Turner luego de 1930, un Cézanne, un Van Goghtiene, para Deleuze, lo desarrollaremos más adelante, un carácter afirmativo de fuga de la intencionalidad sensorial y conceptual. En tanto fuerza afirmativa, esa impresión o conmoción, sacude el marco habitual de disposiciones. Al hacerlo, no se

${ }^{1}$ Deleuze, Gilles. La imagen-movimiento. Estudios sobre cine 1. Barcelona: Editorial Paidós, 1984. 22-23. ${ }^{2}$ Id. 24.

${ }^{3}$ Tales como Pintura. El concepto de diagrama (1981), Francis Bacon: Lógica de la sensación (1981), los estudios sobre cine 1 (La imagen-movimiento, 1983), 2 (La imagen-tiempo, 1985) y 3 (Verdad y tiempo. Potencias de lo falso, 1984), El pliegue (1988).

4 "Quisiera justamente hacerles sentir hasta qué punto [...]. Quisiera apoyarme sobre una serie de "la catástrofe" y ver a dónde nos lleva" (Deleuze 2007 23). 
deja simplemente disponer en él. Más que capturar la impresión (su violencia, su fuerza) disciplinándola, en el orden intencional de la sensibilidad, se trata, para Deleuze, de acoger y acogerse, a su don sin marco. La impresión, la conmoción, la fuerza, su impacto mudo, anida una posibilidad de fuga afirmativa del egoísmo de la sensibilidad, del entendimiento, de las dialécticas de reconocimiento que temen a la diferencia exterior. Para la intencionalidad egocéntrica la acción propia de la sensibilidad y del entendimiento es conocer, reconocer, capturar, capitalizar lo otro en lo mismo, subsumirlo en una episteme. Para Deleuze, se trataría de alterarse a partir de esa impresión, perderse en lo otro que el conocimiento y el reconocimiento habitual, otro que esa impresión, esa sensación, dona. Tentar pensar de otro modo que conocer y reconocer. Alterarse, dejarse alterar más bien, mutar. Pero no como quien cambia de traje, de fantasma, bajo la misma forma, las mismas relaciones de producción, el mismo marco de intencionalidad; sino como quién se deja afectar, robar en una turbulencia que no llega a forma, en la que toda la intencionalidad puesta a captar, concebir, reconocer, muere. Ese pensamiento afirmativamente otro, alterante, desata el ademán, un manierismo análogo al del hecho pictórico. El hecho pictórico es, para Deleuze, fundamentalmente manierista. El manierismo es la torsión que adopta una forma visible, estabilizada, cuando una fuerza invisible se ejerce sobre ella desequilibrándola (Deleuze 2007 70-71), a-formándola. Deleuze define el manierismo "como la relación del cuerpo visible (fenoménico) con la fuerza invisible" (nouménica) ( $f f$. id. 76) que la saca de pose, la contorsiona, la pone a mutar. Mutar no consiste en ir de una forma a otra sumando, capitalizando plasticidad formal, dialécticamente. Mutar consiste, más bien, en aproximarse, merodear formas sin estarse, sin actualizarse en ninguna: metamorfosis. Volveremos sobre esto.

\section{Catástrofe con espectador}

Deleuze se deja llevar por esa impresión a ver “a dónde lo lleva” (cf. 2007 23). Lo hace auscultando una serie limitada de pinturas de catástrofes: catástrofes de tempestad, de avalancha, de hoguera, dice, que en cualquier museo podemos avistar (Id. 42). Catástrofes que se toman toda la tela; o que ocupan un recuadro de ella; o que ni se toman toda la tela, ni ocupan un pequeño recuadro en ella, y más bien flotan por doquier de manera más atemperada (Id. 108). No se trata, sin embargo, de pinturas de catástrofes figurativas, narrativas, representadas en la tela; catástrofes que podemos reconocer, describir, de las que podemos conversar mientras cenamos; catástrofes que por conmovedoras que sean en su representación, no amenazan con desarticular al espectador. Catástrofes con espectador, llamémoslas, aludiendo a la célebre imagen de Lucrecio: “Es dulce, cuando sobre el vasto mar los vientos revuelven las olas, contemplar desde tierra el 
penoso trabajo de otro; no porque ver a uno sufrir nos dé placer y contento, sino porque es dulce considerar de qué males te eximes" (159).

Catástrofes figurativas éstas, que no sólo no amenazan al espectador, sino más bien lo confirman, lo abastecen, lo fomentan. Abastecen el dispositivo de reconocimiento y comunicación en que pintura y espectador se hayan de antemano pre-dispuestos. Pinturas de catástrofes éstas, que no se han indispuesto respecto del campo, del dispositivo pintura que las posibilita y sustenta. Indisposición que podría haberlas convertido en "obras de arte". Porque no habría "obra de arte", no habría "creación", si no se ha pasado por el abismo de tal indisposición. Abismo propio de una catástrofe pictórica de otro tipo. Catástrofe de segundo grado ésta, por así decirlo, catástrofe esencial o acontecimentalmente distinta de la primera, de la figurativa representada en la tela. Catástrofe de segundo grado, entonces, ya no en la pintura, no en la representación, sino de la pintura y de la representación. Catástrofe ya no con espectador, sino del espectador. Y sobremanera de ese espectador primero (princeps) que el pintor es, en cada caso. Catástrofe segunda que afectaría la condición misma de pintar y su posibilidad de reconocimiento como tal acto. Catástrofe del dispositivo pintura del que el pintor, el cuadro/color, el espectador, disponen desde ya para pintar y contemplar. Disponen, eso sí, en la misma medida en que, a su vez, están dispuestos en el dispositivo pintura que dispone de ellos.

¿Qué querría decir pintar en el paso, el pasaje, de la catástrofe `en el dispositivo', 'en la pintura', a la catástrofe 'del dispositivo'? ¿Qué querría decir pintura en el paso por ese abismo? Paso, abismo, sin el cual la creación pictórica no se constituiría como tal; paso, abismo, en que es el lenguaje mismo, la intencionalidad, la comprensión, el mundo como horizonte (in)finito de significaciones, ocupaciones y preocupaciones, lo que entra en catástrofe (de segundo grado)? En este "paso" hay que detenerse. Y Deleuze no pasa de ese paso, se adormila en su turbulencia, su viaje no traslaticio, su mutación, su metamorfosis, su naturaleza muerta.

Sería un retroceso relacionarnos figurativamente con esta catástrofe de segundo grado, intentando consignarla en algún tipo de representación, sea de avalancha, de hoguera, de tempestad; en algún tipo de catastrofismo figurativo, de primer grado. Esta catástrofe segunda no es ya capturable por enunciados. Su performance ha desestabilizado la condición misma del enunciado. Se erige como tal, por así decirlo, en la agonía de los enunciados, la muerte de la intención, del querer decir. Goza, a cambio, de una coreografía, una performance abstracta que enuncia sin enunciado. Libera un campo de escritura y de lenguaje que sirviéndose de enunciados usuarios, profana tal usuariedad, sus marcos de funcionamiento y reconocimiento, en una rigurosa excedencia, como la de la crueldad artaudiana, los 
diagramas de Pollock y de Turner, la figura en Cézanne, en Bacon, en Miguel Ángel, la imagen directa del tiempo en Bresson, en Resnais.

Resulta por lo mismo inconveniente ligar esta catástrofe segunda, como pareciera hacerlo Deleuze en su Curso, a la categoría teológica de creación; categoría propia del régimen figurativo que la catástrofe de segundo grado suspendería. Si la catástrofe de segundo grado es la catástrofe de la usuariedad de categorías o clichés tales como 'creación', 'arte', y en general, de la usuariedad dispuesta del lenguaje en su columbario completo; si como venimos adelantado, Deleuze se deja llevar, alterar, por la fuerza, el impacto de una impresión, una conmoción cuya performance enuncia sin enunciado, a contrapelo de la formalidad y estabilidad reductora del enunciado; si todo esto ocurriera así, como parece que sucede en la primera sesión de su Curso, el 31 de marzo de 1981 (cf. Deleuze 2007 21), ¿cómo es que esa performance muda, afirmativa, puede ser articulada, y tan campantemente entrar en el lenguaje bajo el cliché teológico de creación?

En cualquier caso, no se trata de denunciar, ni mucho menos, una "contradicción" o algo por el estilo, sino básicamente destacar las dificultades propias de la exposición de este asunto. Porque en la medida en que la performance 'creadora', en la medialidad que sea, ocurre a contrapelo de la articulación lingüística, comprensora; aunque a la vez ocurre en ella ocurriéndole a ella, tenemos que internarnos en lo sin palabra, sin enunciado, del único modo que podemos hacerlo, a saber, con palabras, con enunciados, plegando la performance que catastrofea los enunciados, a las categorías catastrofeadas. Usando las palabras, la lengua, la comprensión que se han depuesto, eso si, en el vuelo de una escritura singular que no había. Una cosa es producir enunciados novedosos en la vieja lengua o articulación; otra cosa es reiterar viejas palabras y enunciados en una lengua singular que no había. ${ }^{5}$ Ligando así la catástrofe de la pintura o la catástrofe del mundo, con el nacimiento y la germinación de una pintura, de un mundo, un color singular. Lo liga también a la idea del grado cero del mundo, "del mundo antes del mundo", y también "del nacimiento, el génesis del mundo", (de la Metafísica):

Los grandes pintores jamás hacen otra cosa: pintan el comienzo del mundo. Ese es su asunto. ¿Qué es el comienzo del mundo? Es el mundo antes del mundo. Hay algo que no es todavía el mundo, que es el nacimiento del mundo [...], este amanecer de nosotros mismos [...] es un asunto esencial a la pintura. Los pintores nos ponen frente a eso. La historia del mundo proviene del día en que dos átomos o dos remolinos se han encontrado, dos danzas químicas del color [...]. Este amanecer de nosotros mismos por encima de la nada, los veo crecer, y me saturo de ellos leyendo a Lucrecio [Cézanne] (Deleuze 2007 29).

\footnotetext{
${ }^{5} \mathrm{Y}$ otra más diferente aún, mantenerse vacilando los enunciados en el abismo de una catástrofe de segundo grado, vincula luego, en otros textos, con otros términos.
} 
El nacimiento del mundo, una danza. Vamos entonces de la catástrofe representada en el cuadro a una catástrofe que afecta el acto mismo de pintar, de la articulación pictórica. Sin esta catástrofe no hay posibilidad de 'crear', de pintura, de escritura.

\section{Pintura: ronda mutante del tiempo}

No es suficiente comprender la pintura en relación al espacio: “[...] el cuadro concierne al espacio en tanto encarna una síntesis de tiempo [...], una temporalidad propia a la pintura" (Deleuze 2007 37). Deleuze habla de un tiempo pre-pictórico. El acto de pintar remite necesariamente a un antes de pintar, una condición prepictórica. Antes de pintar ya estaba el mundo, ya estaba la pintura, el a priori material del lenguaje, de los clichés pictóricos, lo pre-dispuesto. ${ }^{6} \mathrm{El}$ acto de pintar en tanto catástrofe segunda empieza en medio de ese a priori material (la catástrofe primera) anterior a que el pintor haga una traza en la tela. La tela está tomada por esa anterioridad. Es dicha anterioridad al igual que el pintor. Hay, entonces, un antes de que el pintor pinte, luego un acto de pintar, de catastrofear, despejar, y

6 "Clichés, por todas partes clichés. Es el mundo de las imágenes-clichés, el mundo concebido como vasta producción de la imagen-clichés. Clichés sonoros u ópticos: palabras, imágenes visuales. Además pueden ser interiores o exteriores. No hay menos clichés en nuestras cabezas que sobre las paredes. [...] ¿Qué quiere decir eso? Que en el interior hay lo mismo que en el exterior, a saber, clichés y nada más que clichés. $Y$ cuando están enamorados es como si contaran a otro de la manera más estereotipada del mundo los sentimientos que experimentan, pues los sentimientos que experimentan son ellos mismos clichés. El cliché está en nosotros. Y nuestra cabeza está llena de ellos, no menos que nuestro cuerpo. De modo que no hay que acusar a las paredes, a los afiches. Producimos los afiches tanto como ellos nos producen. Clichés. No hay más que eso. Es una visión más bien negativa, pero veremos qué podemos sacar. Nadamos en lo negativo: clichés por todas partes, clichés que flotan, que se transforman en clichés mentales, que devienen clichés físicos. Hay que evaluar el peso de la palabra, de las imágenes. Son fuerzas físicas. «iHablen, hablen! ¡Vayan a hablar! ¡Exprésense!», se le dice a la gente. Lo directo es terrible: «Vamos, exprésense directamente!». ¿Pero qué tienen para decir, qué tienen ustedes o qué tengo yo para decir, sino precisamente los clichés de los que, cuando no hablamos, nos quejamos de que se nos imponen? Lo digo porque lo vivo, salvo en casos excepcionales, salvo cuando me preparé bien. ¿Y qué escuchamos en la radio, en la televisión? ¿Qué vemos día tras día? Y cuanto más directo, más patético. Vemos gente que, cuando se la invita a hablar, dice exactamente los mismos clichés contra los cuales protestaba cuando decía «no me dejan hablar». En fin, si piensan en la cantidad de situaciones y de fuerzas sociales que los fuerzan a hablar en la vida, sean lo que sean, incluso en vuestras relaciones amorosas, en vuestras relaciones más personales: «Dime algo...»; comprenden inmediatamente que no es posible experimentar, sentir, ver más que clichés que están en nosotros no menos que en otra parte. «Hable, hable, ¿qué piensa usted de esto?». Y yo digo: «iNo, no, no, paren!». O bien estoy por decir algo y me doy cuenta de que me daría una vergüenza absoluta. Estoy por decir exactamente lo que me hacía reír cuando lo decía otro, y yo me decía: «iOh, que imbécil!». Estoy por decir lo mismo porque no hay dos cosas para decir" (Deleuze 2011 489-490). 
algo sale de allí: el color (Id. 28). Pero el color es condición de la pintura ¿Con qué iba a pintar el pintor, la pintura, si no era con el color? Pero el color es resultado del proceso pictórico, germina cuando la tela ha sido trazada, cifrada. El color es condición, el color es resultado. Pero también es el proceso de la catástrofe segunda de su fabricación, su invención. Todos estos tiempos, este atlas de tiempos, están ya en el cuadro, diferenciándose en la tela, las medialidades múltiples de su escritura que operan como presente retrospectivo de futuros anteriores, una ronda, un turbo temporal. El color brota de esta especie de cocción, de mutación, de presencia que no hace presente.

En lo que se refiere a la disyuncionalidad temporal de la pintura, no se puede no considerar también el hecho de que sus materias, sus medialidades, están hechas de memorias. Una memoria no interior, no psicológica, no sentimental. La tela, los pigmentos, los aceites, las aguadas, las capas cromáticas, constituyen superficies de presente, puntas de presente (Deleuze 1986 136) que el pintor, el montajista va disponiendo según una conexión no predeterminada. Cada una de esas materias, de esas actualidades, es archivo temporal. Capas de memoria, capas de pasado (Ibid.), capas tiempo. Su disposición, su guiso, su cocción, moviliza un devenir archivístico en el que cada elemento está en un génesis permanente sin origen. Mutan ahí las polimatías y politecnias, los clichés, la gestualidad o trazo del pintor, el archivo que el espectador también es. La instalación pictórica de cada trazo es un modo manual ${ }^{7}$ de tratar con esas materias-memorias, esos tiempos; una modalidad de montaje. Su disposición o escritura, en cada caso, su color, constituye una síntesis disyuncional del tiempo en la constelación de pinturas singulares en el dispositivo pintura. En su sola disposición medial la pintura es un block mágico del tiempo, de relaciones de duración sin presente. No pocas veces la pintura singular, su la cerámica que "sale de esta especie de horno que está sobre la

\footnotetext{
7 “Raramente hay espacios enteros en Bresson. [...] Bresson ha sido uno de los primeros en hacer un espacio con pequeños fragmentos, pequeños trozos en los que la conexión no está predeterminada. [...] Espacios que llamamos desconectados, el rincón de una celda, otro rincón, un lugar de la pared, etc. [...] Como si el espacio bressoniano se presentara en series de pequeños trozos, fragmentos, en los que la conexión no está predeterminada. [...] Este tipo de espacios desconectados han sido retomados y re-descubiertos y han servido de inspiración a muchos [...]. Los bloques duraciónmovimiento de Bresson van a tender hacia ese tipo de espacio de conexión no dada ¿a causa de qué se conectan? [...] A causa de la mano [...] y no es teoría, no es filosofía, no lo es, esto no se deduce así. Digo: el tipo de espacios en Bresson y la valorización cinematográfica de la mano en la imagen están evidentemente ligados. Quiero decir: el enlace bressoniano de las pequeñas puntas de espacios, desde el hecho mismo de que son puntas, trozos desconectados de espacios, no puede ser más que un enlace manual. No hay más que la mano que puede efectivamente operar las conexiones de una parte a otra del espacio. Y Bresson es sin duda el más grande cineasta en haber introducido en el cine los valores táctiles (Deleuze 1987).
} 
tela" (Deleuze 2007 33), testifica más que el espectador y se convierte en el elemento temporal, memorialmente gravitante ( $c f$. Didi-Huberman 31 ).

\section{Grisalla}

¿Y si el color no germina? ¿Si en la catástrofe segunda de la pintura los elementos, las estructuras, los planos, la articulación, en fin, todo se funde simplemente uno en otro, y es la ciénaga, la grisalla, la merde? No por nada los pintores no cesan de tirar cuadros dice Deleuze (2007 26). Es preciso que la catástrofe segunda sea controlada. Pero, ¿se puede controlar una catástrofe? (Id. 26, 35).

"El gris es el enemigo del color, el enemigo de la pintura, dice Delacroix". Pero "uno no es pintor mientras no ha pintado un gris", escribe Cézanne (Deleuze 2007 35). Son dos maneras de apuntar a lo mismo. También Klee tiene una nota sobre el punto gris ( 84). En ella lo remite al caos, al caos como catástrofe y génesis. El caos de Klee no se contrapone al orden o al cosmos. No entra nunca en una ponderación. Si se balancea en una ponderación, ya no es un caos. Más que balancearse, entonces, el gris sería el fiel (de la balanza) en que mucho se balancea. El punto de inminencia, la actualidad de una pura inminencia. ¿Inminencia de qué? Inminencia de nada en particular, porque a nada es relativa. En su infinita intencionalidad o plasticidad el lenguaje no podrá decir el caos sin perderlo. En este sentido es álogon. El signo de ese álogon es el punto sin dimensión, virtualidad pura, relativa a nada particular. Un lío, un apelmazamiento, un fieltro entonces, nunca un tejido ni una articulación. Algo que no podemos decir, aunque sí pintar: el gris. No podemos fijarlo en enunciados aunque sí escribirlo, anunciarlo sin enunciados en los enunciados tal como el color se enuncia sin enunciado en trazos precisos. El gris como lógica en pintura, lógica de la pintura, lógica de la sensación. "El punto gris es el encargado de ser el signo pictórico del caos absoluto" (Deleuze 2007 38): ni blanco ni negro, pero blanco y negro; ni arriba ni abajo, porque arriba y abajo; ni cálido ni frío, porque cálido y frío. Virtualidad pura de cualquier color porque virtualidad de ninguno específico. El gris como fiel del color, punto caos desde donde el color irradia una multiplicidad que no hace contornos, no fija ángulos, no llega a enunciado. No hay génesis, no hay nacimiento del color, sin haber pasado por el caos, el gris, la catástrofe de segundo grado.

\section{Hecho pictórico}

"Antes de pintar hay muchas cosas que han pasado" (Deleuze 2007 42), cosas que pesan sobre la tela, sobre el pintor, sobre la mano, el cuerpo. Lo pre-dado o ya dado, lo pre-dispuesto, lo disponible, la disponibilidad que a la vez nos dispone y dispone de nosotros, el dispositivo, el a priori material de los clichés. Todo ello 
dificulta pintar, escribir - salvo que pintar fuera un acto redundante, consular, que abastece y fomenta lo ya dado-. Pintar implica esta especie de catástrofe, de remoción (Id. 51) y despeje de lo que precede, que pesa sobre el pintor aún antes de que haya comenzado. Lo peor, dice Bacon, ya está ahí: la movilización total de los clichés como bestias precipitadas y precipitándose sobre la tela, el cuerpo, el lenguaje, las pantallas, clichés personales no menos que colectivos (cf. Id. 42). El pintor nunca está ante una tela en blanco, una tabula rasa. Él mismo no constituye un punto de partida de nada. ¿Cómo va a escapar el pintor a los clichés si está producido, disciplinado por ellos, si disciplinan, producen, controlan su cuerpo? ¡Lucha contra el cliché! es el grito de guerra del pintor (Id. 58). Si no hace pasar la tela por una catástrofe de segundo grado, no producirá más que clichés.

La tarea del pintor desde siempre ha sido hacer nacer el hecho pictórico a contrapelo de los datos visuales (Deleuze 2007 63). Yo hago marcas, declara Bacon: una especie de limpieza (brouillage). Las marcas de despeje también ayudan (como portulano $^{8}$ ) a que la catástrofe no se hunda en la grisalla. Deleuze, por su parte, denomina diagrama a esta performance doble/triple en la cual giramos desde el comienzo: catástrofe-caos-germen. Cada pintor, cada escritura, en la medida en que pinta, que escribe, constituye un diagrama singular. Cada pintor un diagrama. El pintor tiene que sacar el hecho pictórico de en medio de los datos, los clichés, lo fenoménico predispuesto.

\section{Manierismo}

El hecho pictórico existía desde siempre en la pintura, pero Miguel Ángel lo ha hecho visible (Deleuze 2007 63). Miguel Ángel produjo también un cambio en el estatuto del pintor. Estas dos cosas destaca Deleuze para introducir el manierismo en pintura, el manierismo como pintura.

Antes que un arte bella, que un principio puro de glorificación, la pintura es un arma de guerra de primer orden, más eficiente, incluso, que la letra alfabética, los arcabuces o los lanzacohetes. La imagen sería el modo más eficiente de la evangelización, la alfabetización - la imagen viene ya alfabetizada - (Gruzinsky

\footnotetext{
8 "Nosotros más bien estamos de acuerdo con Pierre Chaunu cuando invoca una larga duración, en la que lo liso y lo estriado se enfrentan en el mar, y en la que el estriaje se instala progresivamente. Pues, antes de la tardía localización de las longitudes, existe toda una navegación nómada empírica y compleja que hace intervenir los vientos, los ruidos, los colores y los sonidos del mar; luego una navegación direccional, preastronómica y ya astronómica, que utiliza una geometría operatoria, sólo opera todavía por latitud, sin posibilidad de 'señalar el punto', sólo dispone de portulanos y no de verdaderas cartas, sin 'generalización traducible'; y los progresos de esta navegación astronómica primitiva, primero en las condiciones especiales de latitud del océano Índico, después en los circuitos elípticos del Atlántico (espacios rectos y curvos)" (Deleuze \& Guattari 488).
} 
90) como evangelización primera. No es por nada, entonces, que su diegética, su ficción, está altamente reglada. Si un Papa, un emperador, hacía un encargo, el pintor no discutía. Pero Miguel Ángel discute (Deleuze 2007 64). Julio II tiene ideas muy precisas sobre lo que requiere de Miguel Ángel: un tema, un relato, un enunciado, una representación estabilizada. El papa pide la Sagrada Familia. Y consigue una Sagrada Familia. ¿Y qué son esos cuerpos desnudos contorneándose al fondo de la tela en un pronunciado manierismo? (ver fig. 1). ¡Ah!, responde Miguel Ángel: son la humanidad antes de la Sagrada Familia, antes de la ley (de Dios). Pero pronto reparamos que el mismo contorneo del fondo había hecho presa también, menos figurativamente tal vez, de manera más atemperada, del primer plano de la tela, de la mismísima Sagrada Familia que se arremolina toda ella como si girara en tirabuzón (la ronda, la danza, la vacilación, la mutación, la performance otra vez). Miguel Ángel se ha servido del tema, de la forma, la ley, lo dispuesto, del cliché encargado por el Papa para, poniéndolo en relación a unas fuerzas sin forma, sin ley, sin tema, y plegando esas fuerzas a la forma, pintar el único asunto, la cosa misma de la pintura, a saber; las fuerzas (la conmoción, la impresión). Antes que pintar la Sagrada Familia, Miguel Ángel pinta fuerzas que ejerciéndose sobre la forma deforman, contornean la forma, poniéndola en turbulencia, como si pintara Bacon. La pintura pinta fuerzas (Id. 69). En otra ocasión, "el regidor de la República de Florencia, Soderini, encarga a Miguel Ángel un cartón con la célebre Batalla de Cascina (ver fig. 2), para que sirviera como preámbulo al fresco que decoraría el Consejo del Palacio Veccio de la capital toscana (Id. 64). ¿Y qué pinta Miguel Ángel? "Un conjunto, una conjunción de jóvenes desnudos con un pronunciado manierismo bañándose en un río, saliendo del agua. Y en el fondo, soldados. ${ }^{9}$ ¿Qué quiere decir esto? Digámoslo otra vez: que a Miguel Ángel no le interesa el tema, la narración, el dato, el cliché. Le interesa el hecho pictórico. ¿Y qué es el hecho pictórico?

1) El hecho pictórico es el mosaico, un conjunto, la coexistencia de figuras en una tela sin que ello cuente ninguna historia, como el que vemos de inmediato en la tela de Miguel Ángel. Un collage, una disposición de elementos conectados por una " $y$ ": hay este, y este, y este, y este... Un juego de posiciones cuya relación no cesa de reconfigurarse, no se estabiliza, no hace unidad narrativa, no cierra. Se aproxima a una y se resbala, y va a otra y se resbala otra vez, y así nos aproximamos a un relato que no llega. Nada hay más opuesto a la unidad de un relato, de un tema, una representación, que lo puramente aproximado.

En varios de sus textos Deleuze expresamente tensa la potencia desestabilizadora de la conjunción " $\mathrm{y}$ ", con la actualidad estabilizada del verbo ser:

\footnotetext{
${ }^{9}$ En medio de esa batalla, un pequeño grupo de soldados florentinos está tomando un baño y son sorprendidos por el enemigo.
} 
En el lenguaje siempre hubo una lucha entre el verbo "ser" y la conjunción "y", entre "es" e "y". Estos dos términos sólo aparentemente se entienden y se combinan, puesto que uno actúa en el lenguaje como constante y forma la escala diatónica de la lengua, mientras que el otro lo pone todo en variación, constituyendo las líneas de un cromatismo generalizado (Deleuze \& Guattari 101).

Lo importante en Godard [...] es la Y griega, la conjunción [...]. Lo esencial es el uso que hace Godard de esta $Y[\ldots]$ porque todo nuestro pensamiento se ha modelado a partir del verbo ser $[\ldots]$. Incluso las conjunciones se valoran por referencia al verbo ser $[. .$.$] . Creo que$ la fuerza de Godard consiste en vivir, pensar y mostrar esta $Y[\ldots]$ haciéndola funcionar activamente. [...]. La $Y$ no es uno ni otro, está siempre entre los dos, es la frontera, porque siempre hay una frontera, pero aquí no hace contornos [...]. Donde hay $Y$, hay relación, no únicamente porque la $Y$ desequilibra todas las relaciones, sino porque desequilibra el verbo ser. La $Y-" y \ldots y \ldots y \ldots$... - es exactamente ese tartamudeo creativo, el uso extranjero de la lengua que se opone a su uso dominante apoyado en el verbo ser [...], la $Y$ griega es la diversidad, la multiplicidad, la destrucción de las identidades" (Deleuze 1999 68).

Las referencias podrían multiplicarse. La conjunción, entonces, es una multiplicidad abierta que cambia, muta, varía continuamente, como un libro. Porque un libro, como cualquier conjunto necesario,

[...] está hecho de materias diversamente formadas, de fechas y de velocidades muy diferentes. Cuando se atribuye el libro a un sujeto, se está descuidando ese trabajo de las materias [...]. En un libro hay líneas de articulación, [...] estratos, territorialidades; pero también líneas de fuga, movimientos de desterritorialización y de desestratificación. Las velocidades comparadas de flujo según esas líneas generan fenómenos de retraso relativo [...] o de precipitación y de ruptura [...]. Un libro es una multiplicidad" (Deleuze \& Guattari 9-10).

Una multiplicidad, un atlas, "una presentación sinóptica de diferencias: ves una cosa y otra cosa distinta colocada a su lado. El objetivo del atlas es hacerte entender el nexo. Cada colocación tiene un significado distinto".${ }^{10}$ No sólo un significado distinto, también una temporalidad diferente. "Cualquier imagen interesante no pertenece a un solo tiempo, cualquier imagen interesante es una confrontación, una coexistencia de tiempos distintos". ${ }^{11}$ La batalla de Cascina, pero también Los bañistas de Cézanne, son una multiplicidad, un atlas. "Es formidable - dice Bacon-, Cézanne ha conseguido meter diez figuras, doce, y las ha hecho coexistir sobre la tela sin ninguna historia que contar" (Deleuze 2007 66). Lo sugeríamos ya,

${ }^{10}$ Georges Didi-Huberman, en el siguiente enlace: https://www.youtube.com/watch?v=WwVMni3b2Zo

${ }^{11}$ Ibid. 
la pintura para Deleuze, como instalación de materias-memorias, es antes que nada una realidad espacio-temporal, un modo de tratar con el espacio y el tiempo.

2) El asunto del hecho pictórico no es pintar cosas visibles. Pinta cosas visibles para captar lo invisible a través de lo visible. El hecho pictórico pinta fuerzas. Las fuerzas son invisibles; las formas son lo visible. El hecho pictórico, ocurre cuando la forma es puesta en relación con una fuerza (Deleuze 2007 69). Las formas son intencionales. Las fuerzas carecen de intención. La fuerza conmocionando, impresionando la forma, es la turbulencia, la contorsión, el manierismo, la deformación de la forma. Pintar una ancha espalda, para Bacon, no es pintar una espalda, es pintar fuerzas que se ejercen sobre la forma, sobre la pose de una espalda (Id. 68). Pintar un grito no es pintar el horror. El horror, es lo figurativo, el cliché visible. El grito es el cuerpo en relación con la fuerza que lo hace gritar (Id. 77) ¿Cuál es esta fuerza? Si respondemos a eso seríamos reenviados a lo figurativo. Las pinturas de Bacon dan la impresión "de cuerpos torturados" (Id. 70). Pero eso responde a una percepción figurativa, psicológica, narrativa. "Si adoptamos una mirada [...] pictórica caeremos en la cuenta de que el cuerpo tiene la posición más natural en función de unas fuerzas" (Id. 48). El hecho pictórico ocurre más intensamente cuanto menos se improvisan, se exageran, se narran, las deformaciones que las fuerzas imprimen a la forma, cuando la fuerza se hace invisiblemente visible, de un modo cada vez más sobrio. "El verdadero aplastamiento del cuerpo no es el bus que lo atropella, sino el hecho cotidiano de que se duerme por la fuerza del cansancio" (Id. 73). Pero Bacon pinta gran cantidad de espasmos (Id. 41).

Hay un tipo que vomita en un lavabo. Pero no vemos el vómito, que es lo figurativo, lo actual; pero sí la torsión, las torsiones del cuerpo, de la espalda. Se trata de movimientos a través de los cuales el cuerpo tiende a escaparse, fugarse, salirse. La fuerza del cuerpo que intenta fugarse por el agujero del desagüe, la que danza sobre el lavabo (Deleuze 2007 80$81)$.

La boca que vomita y la boca que grita no son en absoluto la misma boca. No es la misma fuerza la que baila la maniera del vómito y del grito. También están los gases, los chorros de agua, el orificio de la maguera (ver fig. 3).

3) El hecho pictórico vuelve visible lo invisible. Pintar lo visible es lo figurativo. Con eso hay que trabajar para mostrar lo que no se ve. Así el grupo escultórico del Laooconte (Lessing 1946 40-41) (ver fig. 4). La fuerza del dolor (la pérdida de los hijos del sacerdote) no contornea por una boca abierta, como en el correlato literario del Laooconte en La Eneida de Virgilio donde el sacerdote "al cielo lanza gritos espantosos" (Id.46-47). En el verosímil estético de la escultura de la época, lo imposible es un grito, una boca abierta, un hoyo, la oscuridad, una mancha en la superficie refractante de la piedra lisa. La fuerza del dolor contornea, 
entonces, en el manierismo, la danza, las trenzas musculares de un cuerpo enroscándose, como la Sagrada Familia de Miguel Ángel.

4) El hecho pictórico no transforma. Los pintores, los escultores, no transforman: deforman. El hecho pictórico es la forma deformada (Deleuze 2007 69), la forma en tanto que una fuerza se ejerce sobre ella. No como paso de la forma a lo informe, sino como pasaje, como entre-forma, como aproximación o alejamiento a una forma que no llega. Metamorfosis, entonces, pero no como paso de una forma a la otra, sino como merodeo que no hace forma. Hysteria, la performance o video arte de Sam Taylor-Wood, ${ }^{12}$ o el video arte Death By A Thousand Cuts de Chen Chieh-jen, ${ }^{13}$ en los que el manierismo, la contorsión del rostro en primer plano hace imposible fijar, en cada caso, la pasión, la fuerza del cuerpo: si dolor, si placer, si horror, si llanto, si risa, si éxtasis, etc; en contraposición a las pasiones cartesianas del alma en las pinturas de Jean Le Brun.

El manierismo es la figura de una fuerza ejerciéndose sobre la forma. El manierismo es la relación del cuerpo visible con la fuerza invisible. A eso llamamos coreografía abstracta. En su extremo, el fieltro:

[...] el fieltro [...], un antitejido, [...] no implica ninguna separación de los hilos, ningún entrecruzamiento, sino únicamente un enmarañamiento de las fibras, que se obtiene por presión [...]. Las que se enmarañan son las microescamas de las fibras. Un conjunto imbricado de este tipo no es en modo alguno homogéneo: sin embargo es liso, y se opone punto por punto al espacio del tejido (es infinito por derecho, abierto o ilimitado en todas las direcciones; no tiene derecho ni revés, ni centro; no asigna fijos y móviles, sino que más bien distribuye una variación continua (Deleuze y Guattari 2002 484-5).

\section{Figuras}

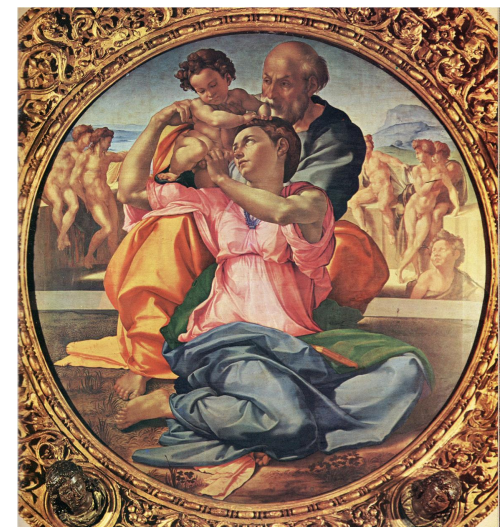

Fig. 1. Miguel Ángel. La Sagrada Familia., c. 1506. Galeria degli Uffizi, Florencia.

\footnotetext{
${ }^{12}$ Enlace: https://www.youtube.com/watch?v=33PZhpay8gM

${ }^{13}$ Enlace: https://www.youtube.com/watch?v=xqqca2EmXa8\&t=42s
} 


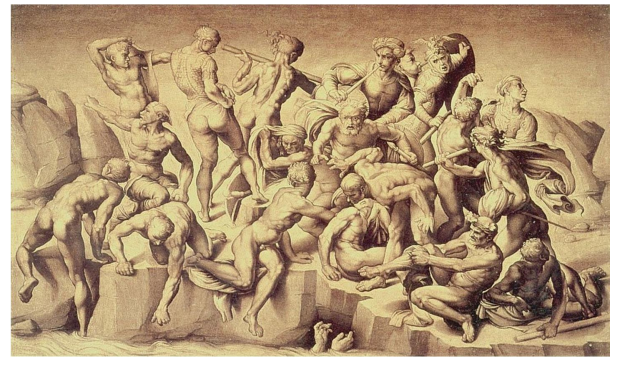

Fig. 2. Miguel Ángel. La batalla de Cascina (copia de Bastiano de Sangallo). 1506. Galeria degli Uffizi, Florencia.

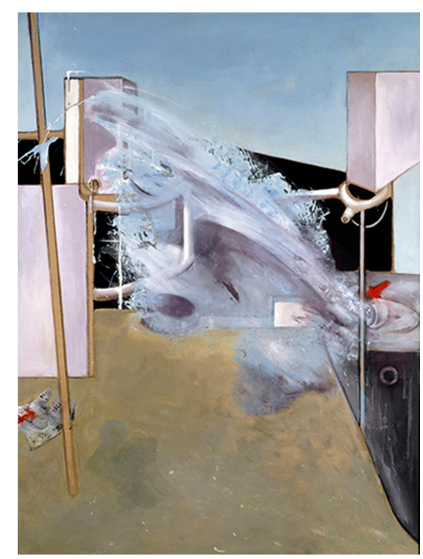

Fig. 3. Francis Bacon. Jet of wáter. 1979. Colección Privada, Suiza.

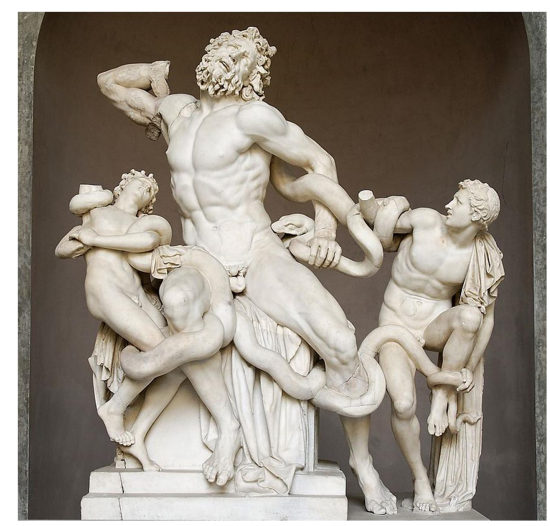

Fig. 4. Agesandro, Polidoro de Rodas y Atenodoro. Laooconte., c. 42 a.C. Museo Pío-Clementino, Ciudad del Vaticano. 


\section{Bibliografía}

Deleuze, Gilles. La imagen-movimiento. Estudios sobre cine 1. Barcelona: Paidós, 1984.

Deleuze, Gilles. La imagen-tiempo. Estudios sobre cine 2. Barcelona: Paidós, 1986.

Deleuze, Gilles. Pintura. El concepto de diagrama. Buenos Aires: Cactus, 2007.

Deleuze, Gilles. Cine 1. Bergson y las imágenes. Buenos Aires: Cactus, 2011.

Deleuze, Gilles. “¿Qué es el acto de creación?”. Conferencia en la FÉMIS (Escuela Superior de Oficios de Imagen y Sonido), París, 15 de mayo de 1987.

Deleuze, Gilles. Conversaciones. 1972-1990. Valencia: Pre-Textos, 1999.

Deleuze, Gilles \& Guattari, Félix. Mil mesetas. Capitalismo y esquizofrenia. Valencia: Pre-Textos, 2002.

Didi-Huberman, Georges. Ante el tiempo. Historia del arte y anacronismo de las imágenes. Buenos Aires: Adriana Hidalgo Editora, 2011.

Gruzinsky, Serge. La guerra de las imágenes. De Cristóbal Colón a Blade Runner (14922019). México: F.C.E., 1994.

Klee, Paul. Teoría del arte moderno. Buenos Aires: Ediciones Caldén, 1976.

Lessing, Gotthold. Lacoonte o sobre los límites de la pintura y la poesía. Buenos Aires: El Ateneo, 1946.

Lucrecio. De rerum natura. Barcelona: Bosch, 1976.

Zouravichbili, François. Deleuze. Una filosofía del acontecimiento. Buenos Aires: Amorrortu, 2004. 